(>)

\title{
EL LANCE DE RECONSTITUCIÓN DEL SÍMBOLO
}

Francisco Guzmán Marín 
Filosofía UIS, Volumen 14, Número 2 julio - diciembre de 2015 pp. 225 - 240

Escuela de Filosofía - UIS

\title{
EL LANCE DE RECONSTITUCIÓN DEL SÍMBOLO*
}

Resumen: El Lógos es la Identidad originaria de donde proviene la estructura de todo ente, ya sea por emanación, escisión y/o fundación; mientras que la razón es la expresión manifiesta de la Inteligencia creadora del Demiurgo, el nous del cosmos. El lógos es tanto la inspiración que revela cuanto el objeto de revelación.

Palabras Clave: Lógos, símbolo, demiurgo, nous, poder.

\section{THE IMPETUS IN THE RECONSTRUCTION OF THE SYMBOL}

\begin{abstract}
The Lógos is the originating identity from which the structure of any entity, whether by emanation, scission and / or foundation; while reason is the manifest expression of the creative intelligence of the Demiurge, the nous of the cosmos. Lógos is both the inspiration as reveals the object of revelation.
\end{abstract}

Keywords: Lógos, symbol, demiurge, nous, power.

Fecha de recepción: junio 29 de 2015

Fecha de aceptación: agosto 19 de 2015

Forma de citar: Guzmán, F. (2015). "El lance de reconstitución del símbolo". Revista Filosofía UIS. Volumen 14, (2). pp. 225-240.

Francisco Guzmán Marín: mexicano. Doctor en Ciencias Sociales por la UAM-X. Profesor-Investigador de la Universidad Pedagógica Nacional México —UPN.

Correo electrónico: coraxthelastone@hotmail.com

* Documento de reflexión no derivado de investigación. 


\section{EL LANCE DE RECONSTITUCIÓN DEL SÍMBOLO}

De ese despojo de lo simbólico surgirá, en el seno del ciclo espiritual, la posibilidad de una revelación manifiesta y exotérica del contenido espiritual. Tal revelación del logos que corresponde al lado manifiesto del espíritu será lo que, en el seno de ese ciclo, podrá llamarse en rigor la razón (lo que desde Descartes y

Galileo podrá entenderse por tal)

Eugenio Trías.

\section{El carácter simbólico del lógos}

¿Cómo se constituye el lógos en cuanto centro de poder y de articulación de la trama histórico-cultural de Occidente? ¿Cómo opera el lógos en tanto agente de representación y significación del kósmos?, incluso, ¿cuáles son las diferentes configuraciones del lógos en el devenir del proyecto de civilización occidental? La tentativa de respuesta a estas cuestiones se enfrenta desde la ruta metodológica que demarca la genealogía nietzscheano-foucaultiana, así, entonces, de acuerdo con Foucault (1991), el Símbolo ( $\sigma u ́ \mu \beta 0 \lambda o v)$ entre los griegos es una técnica jurídica, política y religiosa que consiste en la fragmentación y dispersión intencional de un "secreto", cuyo posterior acoplamiento co-incidente de las piezas/signos, de los componentes/signatura, de los fragmentos/señales, garantiza la autenticidad del mensaje "original". Es un instrumento del poder para conservar la unidad del sistema en la dispersión del devenir y un mecanismo de identificación de los distintos agentes del régimen establecido. El Símbolo es la manifestación por excelencia del poder, confirma Trías (2001, p. 25). Cada hecho — vale decir, cada acontecimiento mundano- deviene señal, signatura y significante por su triple función de indicación, manifestación y significación de la estructura discursiva del mensaje logocéntrico. Así pues, en la perspectiva de las técnicas discursivas del símbolo, las funciones del signo son: indicativa, que designa la existencia del "secreto", en cuanto que la manifestación refiere a la "pre-esencia demiúrgica de 
la conspiración o del pacto" y la significación su carácter de primigenia unidad universal ${ }^{1}$, - pues como apunta José Antonio Antón Pacheco- el símbolo es el ser en su marcha hacia la manifestación (1988, p. 24). El $\sigma \hat{\mu} \mu \beta 0 \lambda o v$ es el reflejo - o la sombra, la evidencia- que denuncia la continuidad del poder, representa su configuración general traducida en un objeto cualquiera que puede ser fraccionado para tornarlo irreconocible, ilegible, intraducible para los profanos; solamente los "iniciados" —o los "cómplices" — pueden reconstituir el símbolo y acceder al "mensaje secreto originario".

En esta lógica, la preservación de la unidad (sym-bálica) trascendental del símbolo, en la dispersión que inaugura la escisión o la cesura original de la existencia, premisa fundante del "acontecimiento simbólico", demanda la presencia de una serie liminar de alianzas que garantizan las condiciones de posibilidad tanto del continuum de poder que instaura y mantiene el devenir del cosmos, al propio tiempo que conjura al jaos (del griego Xáos o Xácos), como de la misma potencia hermenéutica de la estructura simbólica, la cual dispone las condicionantes de intelección, las funciones de los agentes y los dispositivos de revelación del noúmeno secreto, a través de las claves exegéticas, alegóricas, místicas o de elucidación hermenéutica. La auténtica vocación del poder es la de ordenar, significar y revelar, más que reprimir, coaccionar o suprimir como propone la concepción tradicional. El poder se realiza históricamente en la creación de realidad, no en su distorsión u ocultamiento. Esta serie liminar que demanda la unidad trascendental del símbolo se encuentra constituida de las siguientes alianzas: por un lado, la asociación simbolizante-simbolizado, relación significante de los componentes/signatura que conforman al símbolo, donde el primero es la indicación materializada y el segundo es la indicación ausente pero anticipante, providencial, del sentido absoluto que explica el "destino previsto" del mundo, establecido por la conjura o el pacto — conjura de Las Moiras, a cuyos designios se encuentran sometidas las mismas entidades divinas; Pacto Divino entre IHVH y el pueblo elegido de Israel: la Casa de David, verbigracia-; por otro lado, la coalición testimonio-intelecto, comunión empírico-trascendental que constituye la consumación del "acontecimiento simbólico", siguiendo el razonamiento de Trías, es el enlace efectivo entre las comparecencias históricas del Demiurgo, materia revelada, y la conciencia cogitante que atestigua y reconoce la revelación del nomos (vo $\mu \mathrm{os})$ que rige el acontecer ordenado del cosmos — en este sentido, los testigos de las manifestaciones del Ser son el sabio, el filósofo y el científico, mientras que el profeta, el místico y el teólogo son quienes testimonian la previsión y providencia del Dios-; y finalmente, la unión logos-razón, correspondencia

\footnotetext{
${ }^{1}$ Las funciones que aquí se atribuyen al signo, en el caso de Deleuze, se refieren al tipo de relaciones que existen en la proposición, de tal manera que: la designación o indicación es la relación de ésta con un cierto estado de cosas exterior —es un datum—; la manifestación es la relación del sujeto que enuncia y se expresa; y finalmente, la significación es la relación de las palabras con los conceptos universales y de las relaciones sintácticas con determinadas implicaciones conceptuales (Deleuze, G. 1994, pp.15-23).
} 
metafísica del principio generativo que instaura y preserva el plan trascendental que proyecta el por-venir ecuménico en el tiempo, con su imagen manifiesta en la realización histórica de las providencias demiúrgicas, en cuanto pliegue de autoconcienciación —según lo anticiparon Platón y Hegel—, o en tanto que propiedad autorreflexiva —como parecen advertir Heráclito, Descartes, Kant, Spinoza, Galileo y Kepler-.

\section{El logos en cuanto identidad originaria}

El logos es la identidad originaria de donde proviene la estructura de todo ente, ya sea por emanación, escisión y/o fundación; mientras que la razón es la expresión manifiesta de la inteligencia creadora del Demiurgo, el nous del cosmos —es tan sólo el lado manifiesto del espíritu, apunta Trías (2000) —. El logos es tanto la inspiración que revela cuanto el objeto de revelación — toda vez que, como apunta Gadamer: refiere tanto a una facultad del hombre como a una disposición de las cosas (1997, p. 18); por su parte, debido a su "naturaleza" correspondiente, correlato reflexivo del "principio activo" que funda el devenir del mundo, la razón es la facultad del testigo para re-conocer el significado de los sentidos de la revelación y, al mismo tiempo, el principio político, económico, jurídico, ético, estético, gnoseológico, religioso y teleológico de organización histórica de la sociedad humana, conforme a los imperativos revelados por el logos — como bien plantea Pedro Gómez García, la razón fundante se atribuye a sí misma la jurisdicción sobre la realidad, el derecho de dominio: el <<conocer para dominar $>$ cartesiano (1985, s./p.) -

La disposición específica de esta serie liminar de alianzas, determina las pautas de dirección y comprensión de los "imperios del significante", las "formaciones paradigmáticas del lenguaje" y las "reformas del ser" que sustentan y dotan de singularidad histórica a las distintas expresiones del devenir del proyecto socio-civilizatorio de Occidente. Sin embargo, estas alianzas conservan el principio fundamental del "desgarramiento primigenio" que origina al símbolo y, por ende, la lógica dualista, binaria, que caracteriza al devenir histórico del ser humano, desde la comprensión onto-teleológica occidental. Esto significa que persiste una distancia trascendente entre los diferentes elementos que conforman a tales alianzas; por ello mismo, debido a su condición derivada, proveniente, el simbolizante, el intelecto y la razón son desbordados en sus propiedades de significación y de comprensión, por losimbolizado, el testimonio y el logos. Es verdad, el simbolizante es la manifestación material del símbolo, en tanto que el intelecto es la facultad del testigo para reconocer la revelación que testimonia la presencia del Demiurgo y la razón es el reflejo temporal, histórico, del logos; pero todos ellos acusan una existencia insuficiente, una deficiencia ontos-lógica, una determinada minusvalía constituyente, toda vez que su potencia hermenéutico-significativa e, incluso, la pertinencia de su misma presencia sólo encuentra sentido en la 
realización del "acontecimiento simbólico", en tanto efecto del exceso definitorio de los extremos trascendentales de la alianza. Lo propio de lo simbolizado, el testimonio y el logos es la "ocultación revelante", la "ausencia anticipante" —la alétheia, en términos griegos_-; por cuanto su exceso de significación desborda la capacidad comprensiva del simbolizante, el intelecto y la razón. Siempre es posible advertir, intuir, anticipar un dejo de comprensión que se escapa, un remanente de sentido que se escabulle tras telones de la revelación, puesto que es propiedad del Ser y de la divinidad la des-ocultación. Por esta razón, el pensamiento griego comprende la verdad como alétheia, juego metafísico de ocultación-desocultación, comparecencia descubierta y encubierta del voũc. Luego, para salvar la distancia instaurada por el desgarramiento original del símbolo, es necesaria la existencia de ciertos dispositivos de mediación que permitan establecer la comunicación metafísica entre los extremos y conformar la disposición particular de la serie liminar de alianzas, de esta manera: entre el simbolizante y el simbolizado se sitúan las "claves hermenéuticas de sentido", como les denomina Trías — a saber: exegéticas, alegóricas, místicas o de elucidación-; mientras que el "método" se emplaza en cuanto enlace del testimonio y el intelecto (por prescripción litúrgico-ritual, némesis mayéutica, derivación lógica, autorreflexión metódica, autoconcienciación sintética, metafísica hermenéutica, diálogo experimental); y, por su parte, la correspondencia trascendental logos-razón demanda la presencia del fármakon, en cualesquiera de sus representaciones históricas, entre ellas: el héroe trágico griego, el libertador-pastor, el profeta hebreo, el Mesías cristiano, el revolucionario marxiano, el especialista disciplinario, pero siempre como víctima propicia, bajo cuyo sacrificio personal se sutura el primigenio desgarramiento, mediante la renovación del pacto o la conjura, en tanto el miasma que asola al mundo es depurado a través de la katharsis (Ká $\theta \alpha \rho \sigma ı)$, el rito o la gnosis ( $\Gamma \omega \omega \sigma \iota)$, y el ser humano es redimido como consecuencia del restablecimiento del orden cósmico: la conquista de la unidad original. La resolución sintética del Ser, por medio de la desenajenación de la conciencia.

Así, la cesura de la alianza simbólica que subyace entre la historia humana y la previsión demiúrgica es conjurada por efecto de la ofrenda trágica: el sacrificio del fármakon, del héroe trágico griego, del Emmanuel en la tradición judeo-cristiana, del héroe revolucionario, del erudito moderno. La culpa de la diferencia que desgarra al ser humano del "orden natural" instaurado por los dioses, o por la mecánica física del universo — fuente del miasma que asola a la existencia en el mundo, condenándola a la inexorable corrupción y, por ende, a la tragedia de la muerte- - es expiada en la entrega ritual, de la donación de sí mismo, de la fatal verificación de la providencia — del oráculo, de la profecía o de la anticipación teorética-, con lo cual se restaura la alianza entre la sociedad humana y las fuerzas que gobiernan la existencia, según puede colegirse de los planteamientos de Ernest Becker (1992). 
Ahora bien, por tanto el logos es el principio generativo que instaura y preserva la realización del plan trascendental que dispone el por-venir del mundo en cuanto manifestación temporal, éste deviene razón histórica, dispositivo de mediación entre las previsiones demiúrgicas — del Ser o de la divinidad-y las formaciones socio-culturales, así como de los enigmas hermenéuticos de la revelación; y la res cogitans del ser humano, en su condición de conciencia testimoniante de la existencia. La disposición concreta del logos, en su manifestación de razón histórica, se expresa mediante la trama de la proyección socio-cultural, es decir, del envío de civilización. La cultura se define por el conjunto significativo de la práctica humana, mientras que la civilización es el plegamiento depurado de un segmento significante de esta misma práctica, pero como proyección predestinada en la historia (dispuesta por la previsión divina, por la dialéctica de las leyes socio-históricas o por la teleológica intención socio-política; "la civilización es el inevitable destino de toda cultura", sentencia Splenger, hacia el principio del parágrafo 12 de La Decadencia de Occidente), esto es, en cuanto "proyecto histórico" que determina el destino trascendente de la sociedad humana y, en consecuencia, de todos los seres del mundo. El sino del cosmos se encuentra inexorablemente relacionado con la suerte del ser humano. En este sentido, la razón presencia dos modalidades, a saber: la "mundanización del logos" en su comprensión de "paradigma racional" del devenir socio-histórico — proyecto de civilización determinado por prescripción divina o por resolución de la dialéctica social; devenir de la Idea en Espíritu Absoluto o materialización histórica de la Utopía- y el cógito cogitans en su emplazamiento de facultad testimonial del ser humano. Res histórica y res cogitans. Razón que se impone sobre el devenir del mundo y Razón que se afirma como uno de los factores dentro de éste, como plantea Whitehead (1999).

En su primera modalidad de presencia, a causa del carácter correspondiente trascendental que guarda con la identidad originaria, se manifiesta de manera jurídica, toda vez que proporciona la ley y la justicia que gobiernan los derroteros de la historia, es decir, se trata de una razón nomotética, legislante y judicial. La ley es la razón que impone el orden sobre el mundo y, por ello, permite su comprensión inteligible; mientras que la justicia es la "determinación de la pena que deben padecer todos los seres por su injusticia en el orden del tiempo", según advierte Anaximandro y cuya máxima sentencia se manifiesta en la terrible presencia del rostro de la Gorgo, ila muerte! La ley de la razón histórica en-causa el "Destino" humano (trama fatal de las Diosas de la Necesidad, Providencia divina, por eso mismo el término en-causa comporta los dos sentidos: causa de y encauzamiento fenoménico) y, por su parte, la justicia establece la distribución jerárquica de las estructuras ontológicas —el orden gradual de los seres del cosmos, en función de su proximidad con la razón, la conciencia o el espíritu-, además de sancionar la existencia de cada ente, en relación con el "recto" seguimiento de las prescripciones establecidas por la ley. La justicia histórica es el tribunal que somete a examen y a prueba los comportamientos existenciarios de los entes, con 
el propósito metafísico de decidir el destino trascendental que les corresponde —la degradación o el ascenso en el circuito de la trasmigración de las almas, en la concepción pitagórica; la condena o la salvación, en la tradición judeo-cristiana; sin olvidar la censura o la vindicación histórica, en la lógica revolucionaria—, así como la difusión de los "bienes onto-históricos" de que deben participar por su compromiso con la ley -las partes o los lotes del "botín" que a cada ente le "tocan", afirma Trías (2000, p. 127)—. La acción de la justicia histórica define series de evolución, vectores de desarrollo, genealogías de destino, mundano o trascendental, conforme al desempeño existenciario de los entes. La ley y la justicia establecen circuitos ontológicos de devenir existencia, así como formaciones de inteligibilidad del cosmos. Por esto, dentro del contexto de la experiencia humana, la res histórica, a través de la intervención dialéctica de la ley y la justicia que establece el nous de la evolución, el desarrollo o el progreso, determina las pautas de orientación del proceso general de racionalización socio-cultural, en cuanto "Historia Universal" de la especie. Toda vez que en su aparente dispersión racial, cultural y ontogenética, el género preserva la unidad trascendental que define su existencia mundana, en la conformación orgánica de la "Sociedad Humana"; entonces, los seres humanos, tanto en lo individual como en lo general, participan de un destino común que se manifiesta, material y espiritualmente, en las disposiciones para reformar al Ser que proyecta la denominada "Historia Universal", ya sea como predestinación trascendental o en tanto recuento de la experiencia socio-civilizatoria. En esta lógica de pensamiento, Occidente emplaza su tradición histórica particular, como la síntesis paradigmática de la Historia Universal, en cuanto proceso de racionalización de la sociedad humana mediante el proceso socio-civilizatorio. La historia de la civilización se constituye en la paradójica relación del proceso de reconocimiento de la razón que organiza al cosmos con el proceso de racionalización del mundo.

Por su parte, la res cogitans, como segunda modalidad de presencia de la razón y en cuanto expresión manifiesta de la inteligencia del Demiurgo, dispone de las pautas de desciframiento de las claves hermenéuticas de sentido, a las cuales debe sujetarse el pensamiento, así como de los imperativos de racionalización histórica de la sociedad humana. Es una razón de carácter ético-gnoseológica y ético-teolológica. Ético-gnoseológica porque determina las formas del recto pensar, del recto enunciar y del recto proceder para aproximarse a la verdad, de acuerdo con las disposiciones metafísicas de la divinidad Parménides, cristianismo_-, de la Idea arquetipo —Platón, Hegel—, de las causas eficientes y/o finales del Ser —Aristóteles, Whitehead-, así como de las condiciones trascendentales de la comprensión fenoménica —Kant—; o bien, por conveniencia con las estructuras ontológicas del sistema universal de las fuerzas gravitacionales - física newtoniana-, de los vectores evolutivos de la entropía — física termodinámica—, de los "estados posibles" del sistema-cosmos — mecánica cuántica-, de la dinámica auto-organizativa y de las estructuras disipativas de los sistemas dinámicos inestables — física de no equilibrio, teorías 
del caos-, de la configuración lógica de los hechos que conforman la realidad (el primer Wittgenstein del Tractatus, "Was jedes Bild, welcher Form immer, mit der Wirklichkeit gemein haben mub, um sie überhaupt —richtigoder falsch—abbilden zu können, ist die logische Form, das ist, die Form der Wirklichkeit" (1981, pp. 46-47) $)^{2}$, de las mediaciones sígnico-simbólicas que determinan las relaciones humanas —semiótica, hermenéutica-, además de las condiciones trascendentes que establece el desarrollo ontogenético del ser humano para la construcción apropiativa del conocimiento —-Piaget—. El recto pensar proviene de la necesidad de concordancia con la ley y la justicia que norman el devenir del objeto de revelación, puesto que son éstas quienes definen su posible inteligibilidad, para lo cual es indispensable liberar al pensamiento de las "falsas apariencias" y cernir las experiencias que fundamentan sus reflexiones - "Has de aprender, con todo, aun éstas \{las opiniones de mortales en quien fe verdadera no descansa\}, porque el que todo debe investigar y de toda manera preciso es que conozca aun la propia apariencia en pareceres" (1996, p. 36), le anticipa la Demonio a Parménides-. El recto enunciar demanda la formalización lógico-sistemática de las disposiciones discursivas, con el propósito de exponer de forma manifiesta las "estructuras lógicas" del nomos universal, para describir adecuadamente la dimensión narrativa de la naturaleza, de acuerdo con Prigogine (1996). Si existe una correspondencia lógico-formal entre las estructuras del lenguaje y las estructuras del cosmos, según fue planteado antes, luego entonces, las disposiciones discursivas que dicen al mundo deben detentar un carácter lógico formal. El recto proceder es tanto la reforma ontos-lógica del ser humano, a través de la formación epistémicognoseológica apropiada para reconstruir la verdad orgánica del cosmos, como las secuencias procedimentales que conforman el método adecuado de revelación, conforme a los principios del conocimiento que instaura el sistema de racionalidad logocéntrico. El propósito nodal de estas formas ético-gnoseológicas es la revelación de la verdad —el desciframiento del "pensamiento de Dios", como le denomina el físico Stephen Hawking (1989) — . Desde este punto de vista, el lenguaje, representa el vehículo de la verdad, el intelecto, la facultad testimonial de desciframiento de las claves hermenéuticas que significan los hechos del mundo, el método, la emergencia procedimental de revelación, la formación epistémico-gnoseológica, la depuración de las capacidades ontogenéticas, de percepción y del espíritu para la apropiación intelectiva del mundo, en tanto que

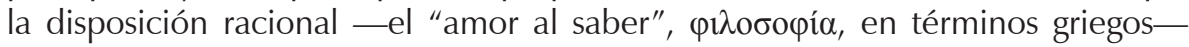
manifiesta la autoconciencia del Demiurgo — del Espíritu Absoluto en Hegel, de la materia en Marx, del ser social en Jesús Ibáñez- en el proceso de reconocimiento y exploración de sí mismo. El cosmos, a través de la conciencia humana, se manifiesta como una estructura existenciaria autoconciente.

\footnotetext{
${ }^{2}$ En la traducción de Enrique Tierno Galván, significa: "Lo que cada figura, de cualquier forma, debe tener en común con la realidad para poderla figurar por completo — -justa o falsamente- es la forma lógica, esto es, la forma de la realidad" (Wittgenstein, 1981, pp. 48-49).
} 
Debido a su disposición hacia la verdad, la res tiene la función sustantiva de examinar, evaluar y reconocer las piezas significantes, así como entender las relaciones de significación que traman y permiten la reconstitución trascendental del símbolo que conforma y explica la unidad original del cosmos. Tal es el objetivo fundamental de la res cogitans en su carácter ético-gnoseológico. El desciframiento de la verdad, en esta perspectiva, asigna una doble función a la existencia del ser humano: por un lado, en su posición de conciencia testimoniante tiene el deber onto-teológico de apropiarse intelectiva e instrumentalmente del mundo natural, para disponer la impersonalidad del sistema material que lo con-forma en ecumene, es decir, para adecuarlo a la voluntad y a las necesidades humanas, sean éstas de carácter espiritual o histórico — purificación de la objetividad que la dispone para la recepción del espíritu, en términos hegelianos-; y por otro lado, en su situación de ente exiliado de la unidad del Ser tiene el deber onto-teleológico de reformar su propia estructura existenciaria a la racionalidad que gobierna al universo, con el propósito de redimir la corrupta condición humana. Puesto que la absolución del ser humano comporta la conversión hominizante del orden universal, a través de la acción conjunta de la apropiación intelectual e instrumental del cosmos, que permite el develamiento de las claves hermenéuticas de sentido, y la "reforma del ser" —social y natural—, lo cual posibilita la racionalización del devenir histórico, con el objeto de superar la degeneración ontológica que produjo la trágica fractura de la unidad primigenia; ambas funciones establecen una relación metafísica correspondiente y complementaria, en tanto que la hominización comprensiva y objetiva de la naturaleza se corresponde con la reforma humana, en el proceso de redención de la existencia, simultáneamente, la superación ontológica de las estructuras del mundo natural complementa la depuración onto-teleológica de las estructuras existenciarias del ser humano. De este modo, parafraseando a Eugenio Garin —a propósito de la función de la astrología en el pensamiento renacentista—, la reforma del Ser no se plantea tanto la "naturalización" humana, como la "humanización" de la naturaleza. La conversión ecuménica del cosmos -la transformación del universo en el tabernáculo de Dios, en la "casa del ser humano" - y la redención humana conforman la Unidad Sim-bálica del Ser, del Espíritu, de la esencia divina en su devenir mundo —Dios al desarrollarse deviene el mundo, apunta Hegel (1997, p. 123)—. De esta manera, siguiendo el razonamiento hegeliano, la Historia Universal es el devenir de la existencia fragmentada — que propicia el extrañamiento y la enajenación del Espíritu — en Unidad Absoluta de la Sociedad Humana, de la especie, del género, sin importar sus diferencias socio-históricas; puesto que, todos los seres humanos comparten la misma constitución biológica, el mismo "mundo físico" y la misma disposición trascendental hacia la verdad, incluso el pensamiento y la común dotación original del ser humano, el pensamiento y la común dotación original del ser humano, la razón y el lenguaje, acaban uniéndonos a todos, como afirma Gadamer (1999, p. 148) Unidad conciente. Reconciliación metafísica. Reconstrucción histórica del Símbolo. 
La existencia del ser humano, como producto de la dialéctica histórica que imponen los imperativos categóricos (onto-teológico y onto-teleológico), encuentra su auténtico significado en la misión de expiar el mal del mundo, mediante la depuración progresiva de la práctica cultural y de los procesos naturales que produce la realización del proyecto de civilización de la Sociedad Humana en su totalidad. En la perspectiva de la tradición judeo-cristiana, como advierte Rüdiger Safranski, la irrupción del pecado original provoca una grieta, un desgarro fundamental en la unidad de la creación, tras lo cual el ser humano es expulsado del paraíso y condenado por la voluntad divina a la reproducción material de la especie, teniendo como fondo existencial el dolor y el trabajo. En tal contexto, a la humanidad no le resta más que refugiarse en la civilización, tanto como un medio de ennoblecer el trabajo y la generación, indica Safranski (2005); también en cuanto recurso histórico para resarcir la unidad fracturada por la intromisión del mal en el mundo. De esta suerte, la historia de la civilización comienza con el cisma de la creación y la sustracción de la humanidad del seno divino. Ahora bien, en tanto que el conjunto de los seres humanos constituyen una sola especie en el orden de la existencia, en consecuencia, conforman una misma sociedad con un destino socio-histórico en común que define el trazo sustantivo de la Historia Universal. La dispersión de la humanidad en diversas formaciones de estrato socio-cultural denota la fractura que propicia el advenimiento del mal en la creación, pero no compromete la Unidad fundamental que la distingue como especie en el orden de la existencia, ni tampoco el destino que le es propio en el advenimiento del universo. La unidad ontológica de la Sociedad Humana, reflejo de la Unidad del Ser, es el garante trascendental de la unidad de su experiencia histórica. La civilización, en cuanto refugio del ser humano para resistir la condena divina y estrategia de resarcimiento de la unidad fracturada, se afirma en el reconocimiento de la ius que gobierna al cosmos — sea en su carácter metafísico, ontológico o histórico- y de la reforma del ser que demandan sus imperativos categóricos, con el objeto de posicionarse como el proyecto definitorio de los destinos de la humanidad entera, toda vez que los seres humanos conforman el devenir de la unidad en el tiempo. En cuanto el proyecto civilizatorio proviene del reconocimiento de la verdad que comporta el conocimiento de la ley y de su consecuente materialización instrumental, adquiere dos características fundamentales, a saber: la universalidad y la necesidad. Si la civilización tiene como objeto la salvación, entonces, comprende a la totalidad del género humano y es inevitable su concreción en el mundo, puesto que son las fuerzas sociohistóricas, instauradas por los envíos del Ser o por la providencia divina, quienes deciden su resolución trascendental, ya sea por prescripción de la omnisciencia de Dios en la tradición judeo-cristiana, la acción de la dialéctica sintética de factura hegeliano-marxista, la intervención de los factores de "selección natural" de inspiración spenceriana, o por la propia lógica de desarrollo que establecen los agentes socio-civilizatorios de acuerdo con el análisis de Norbert Elías (1994b). Desde este punto de vista, la estrategia reconstituyente del $\sigma 0 ́ \mu \beta 0 \lambda o v$ en cuanto envío histórico, compele al proyecto socio-civilizatorio de Occidente a conjurar 
la diferencia y la individualidad, en tanto formas autónomas de existencia, como premisa necesaria de los procesos de racionalización socio-cultural. Puesto que la diferencia y la individualidad, en cuanto manifestaciones autónomas de la existencia, sólo encuentran su auténtica razón de ser, así como su significado ontológico y su sentido histórico en la anticipación y en el reconocimiento de la unidad trascendental que preserva y reproduce el orden, en el disperso acontecer del cosmos. La diferencia y lo individual explican su presencia sólo como fragmentos del todo que conforma el símbolo.

Luego, por cuanto el problema de la inteligibilidad del mundo se encuentra asociado inexorablemente al destino humano, como parece anticipar Epicuro, entonces, la reconstitución del $\sigma u ́ \mu \beta o \lambda o v$ sustenta dos acciones históricas que dispone la res cogitans en su carácter ético-teleológico, en cuanto correlato de las funciones que establece la voluntad de verdad, a saber: por una parte, la participación instrumental de los dispositivos legales, procedimentales y materiales, construidos por la razón en su búsqueda de la verdad, para concretar la transformación ecuménica del mundo, así como para la reforma sistemática del ser; y por otra parte, la racionalización de los procesos históricos que con-forman a la "Sociedad Humana", con el fin de restaurar la unidad original fracturada por la irrupción del mal en el mundo (efecto metafísico de la rebelión del Arcángel Luzbel, la seducción y la desobediencia de la pareja primigenia en la perspectiva judeo-cristiana, la fractura del Alma Universal y su aprisionamiento en la corrupta materialidad del cuerpo siguiendo los planteamientos platónicos, el extrañamiento de la conciencia del Espíritu en la dialéctica hegeliana o la instauración de la propiedad privada en la concepción engeliano-marxista), a través de lo cual se constituyen las condiciones de posibilidad para alcanzar la prometida redención trascendental del género. Reflexionar sobre el devenir del universo comporta la restauración del ser humano en la Unidad del origen.

En consecuencia, la res cogitans adquiere una disposición instrumental, mientras que la historia humana se comprende como la "penitente odisea que debe "padecer" el ser humano en su conquista de la salvación, tras la caída" — por eso afirma Splenger (2007) que la transición histórica tradicional de Occidente presenta "los caracteres religiosos de una salvación" —; es la aventura del Ulises, enfrentando la condena divina, sorteando las hechiceras tentaciones y las engañosas quimeras con que pretenden perderlo los entes malignos para desviarlo de su sino, en su retorno a Ítaca, en su regreso a la fuente de procedencia. La Historia Universal se comprende y se expone como la lucha de los impulsos ordenadores de la civilización, contra la entropía de las fuerzas de la barbarie y del salvajismo que provienen de los instintos en su estado natural. La condición natural del ser humano contradice la unidad que conforma la disposición trascendental de la especie, porque la mantiene en estado de guerra permanente —al menos en la versión hobbesiana-, mientras que los instintos le encadenan a las disposiciones de su indigencia mundana. La civilización somete a la unidad que le es propia al ser 
humano - por la acción civilizatoria no somos individuos: somos especie, plantea Schiller (1990, p. 142)—y, al mismo tiempo, domina el barbarismo de las fuerzas de sus instintos. La civilización, de esta manera, es el proyecto de depuración progresiva de la condición humana. La razón instrumental que conduce este proceso histórico de superación de la situación del ser humano, paradójicamente, tiene como punto de partida el re-conocimiento de la ley y la justicia, impuestas por la inteligencia del Demiurgo, que gobiernan y hacen patente la inteligibilidad del devenir del sistema natural, las cuales se disponen como principios rectores de la reforma intelectual, ética, socio-política, económica y ontológica; sin embargo, una condición necesaria del proceso de redención es el trastrocamiento del "orden original" que priva en la naturaleza, para imponer la forma propia de la racionalidad del ser humano. Se trata de un cambio de orden legislativo, esto es, la transformación de la impersonal "ley natural" en la disposición teleológica de la "ley racional". Encuentro metafísico del Lógos absoluto y del lógos relativo. Reconciliación espiritual de la Conciencia Absoluta con la Conciencia Testimonial. Síntesis dialéctica de la Idea y la objetividad concreta, en términos hegelianos. Comunión de los fragmentos con y en el todo; resarcimiento de la fractura, restablecimiento de la Unidad Simbólica. Entonces, el proyecto de civilización se traduce en la disposición de racionalizar los procesos de la existencia mundana, con la finalidad de alcanzar la salvación, de reconquistar la unidad original.

Así pues, la razón ético-gnoseológica dispone la dirección de sentido, las normas y los medios de transformación ontológica, de acuerdo con las previsiones establecidas por la inteligencia del Demiurgo, mientras que la razón ético-teleológica instituye las pautas necesarias de la reforma del ser — "la mejora de la condición del ser humano", advierte Bacon (1985)—, con el objeto de alcanzar la redención cósmica y, en consecuencia, conquistar la felicidad humana, bien sea por retorno al seno de la divinidad, o bien, por realización científico-tecnológica, exorcizando el mal del mundo. De esta manera, la res cogitans en su carácter ético-gnoseológico es la fuente de procedencia de $U$-topos, representación del Ideal Histórico que dirige la corrección ontológica del ser humano, a través de la acción socio-política, educativa, económica, científica y/o religiosa. La "utopía", desde este punto de vista, significa tanto el impulso correctivo del ser humano como la dirección del sentido histórico de la Sociedad Humana, por medio de la intervención reformadora de los envíos de la segunda modalidad de presencia de la razón. En síntesis, el carácter ético-gnoseológico posiciona a la razón hacia el revelamiento legítimo de la verdad del Ser, de Dios, de la mecánica universal y/o de la dinámica del cosmos; en tanto que el carácter ético-teleológico la emplaza como vector histórico de la redención humana, mediante la doble reforma del ser: depuración del ser humano y hominización de la naturaleza. Doble carácter que dispone a la res cogitans en la modalidad histórica de razón instrumental. 
Por esta razón, el lance de reconstitución del símbolo es algo más que un simple mecanismo de reconocimiento de la conjura del poder; por el contrario, viene a ser la fabulación de los principios constituyentes, de las disposiciones de comprensión y de las formas operativas del sistema de racionalidad impuesto por los envíos del Lógos, en cuanto trama histórico-cultural —Proyecto de Civilización-, desde la misma Herkunft de la proyección histórica occidental. De esta suerte, el Lógos se emplaza en el devenir de la experiencia humana como el "Paradigma de Racionalidad" que dispone: la trama del destino socio-histórico, los modos de apropiación intelectiva del mundo y las formas de corrección ontológica del ser humano y de la naturaleza, materializado en las formaciones socio-culturales del proyecto civilizatorio de Occidente. De acuerdo con los planteamientos expuestos antes, respecto de la reconstitución del símbolo, el Lógos es tanto el fundamento metafísico, en la modalidad de Res Histórica, como el principal parámetro de legitimación procedimental del "conocimiento verdadero" y de la "existencia humana", sin soslayar su función de agente reformador dentro de los procesos de redención del ser, en la modalidad de res cogitans. La exigencia de legitimidad que demanda el Lógos del revelamiento de la verdad y de las condiciones de la existencia humana, formaliza tanto las disposiciones discursivas que representan la esencia divina, matemática, mecánica o lógica de los acontecimientos mundanos, como la experiencia reminiscente, espiritual, mental, sensorial o psicológica que los reporta a la conciencia del ser humano. Por cuanto la racionalidad legal que organiza el devenir del mundo y la inteligibilidad manifiesta que permite su comprensión humana tienen un carácter formal, entonces, la revelación del nous debe prescindir de la materialidad que caracteriza tanto al fenómeno como a su percepción sensible, con el propósito de meditarlo en su forma pura, en su más íntegra manifestación racional. La intelección perfecta de la razón que estructura el acontecimiento ordenado de la existencia sólo es posible mediante la sujeción de las "leyes naturales" a los principios formales de las "leyes de la intuición y del pensamiento" —según parecen coincidir Kant y Schelling-. Desde esta perspectiva, la verdad del Lógos constituye un saber formalizado y formalizante del discurso y de la experiencia del ser humano.

El proceso de formalización de los procedimientos de producción y enunciación de la verdad, en la historia de Occidente, establece el tránsito gnoseológico de la disposición de verdad poético-religiosa a la formación de verdad filosófico-metafísica y de ésta a la actual conformación moderna de la verdad científico-ontológica (del pensamiento mítico-mágico al pensamiento lógico-metafísico y finalmente al orden objetivo, según la concepción comtiana). El proceso comienza con el ritual de iniciación platónica que transforma la jovial inocencia del joven poeta trágico en el filósofo pesimista, mediante la purificación del fuego, para después, ya en la plena madurez intelectual kantiana, a través de la formalización trascendental de la experiencia del conocimiento, convertir el acto de revelación de la verdad en un procedimiento técnico de lógica matemática. Así, de acuerdo con Ingolf Ahlers (2000), para Kepler y Galileo 
la capacidad del entendimiento matemático y astronómico del ser humano lo asemeja a la divinidad. El poeta-profeta, oráculo de los dioses, cede ante la tenaz suspicacia metafísica del filósofo-especulativo, heraldo del Ser, quien no puede contener el avance de la escéptica matema del científico-disciplinario, reportero de la legalidad estructural del mundo. En este devenir formal de la voluntad de saber, la propia fe debe ser desprovista de todo resabio de mística pöiética, para someter el conocimiento de la divinidad a los postulados de la razón —según se lo propuso el movimiento escolástico, en la tradición cristiana-; de esta manera, la teología se transforma en la racionalidad hermenéutica que devela los dictados de la divinidad, por medio de la formalización de la fe. La religión sólo representa otro medio de aproximación al desciframiento del código secreto que con-forma al símbolo. Aún la historia del arte denuncia esta tendencia hacia el formalismo. La verdad trascendental demanda un pensamiento y una experiencia también trascendental, puesto que el interés estriba en librar a la forma del contenido y en conservar lo necesario, puro y libre de toda contingencia, como previene Schiller a propósito de la "filosofía trascendental" (1990, p. 143). Evolución epistemológica de la voluntad de saber. Materialización histórica de la intuición comtiana. Así pues, la disposición simbólica del Lógos es un emplazamiento proto-típico de comprensión histórica que direcciona los procesos de producción del conocimiento, las formas de construcción de la identidad y las estrategias de acción política, económica, jurídica, ética, estética y teleológica occidental. En cuanto paradigma de la experiencia humana en el mundo, el logoi pretende un carácter universal, necesario y trascendental —o trascendente-, que interviene como principio organizador de la experiencia histórica del devenir cultural de Occidente, desde su misma Herkunft y Entstehung, es decir, desde su propia fuente de procedencia y emergencia socio-histórica, así como de los destinos de la "Sociedad Humana", al posicionarse en la dimensión planetaria, como el proyecto de civilización universal por antonomasia. La Historia Universal de la humanidad, desde este punto de vista, se sintetiza en el devenir del proyecto socio-civilizatorio occidental, a través del paulatino proceso de depuración formal histórica de la condición humana $\Phi$

\section{REFERENCIAS}

Ahlers, I. et. al. (2000). La genealogía del cristianismo: ¿Origen de Occidente? México: CONACULTA.

Antón, J. (1988). Symbolica Nomina. Barcelona: Hogar del Libro, S. A.

Bacon, F. (1985). The Essays. Londres: Penguin Books.

Becker, E. (1992). La lucha contra el mal. México: Fondo de Cultura Económica. 
Deleuze, G. (1994). Lógica del sentido. Barcelona: Planeta-Agostini.

Elías, N. (1994). El proceso de la civilización. México: Fondo de Cultura Económica.

Foucault, M. (1991). La verdad y las formas jurídicas. Barcelona: Gedisa.

Gadamer, H. G. (1997a). Mito y razón. Madrid: Paidós.

Gadamer, H. G. (1997b). Verdad y método I. Salamanca: Sígueme.

Gadamer, H. G. (1999). Poema y Diálogo. Barcelona: Gedisa.

Gómez, P. (1985). "Para criticar la antropología occidental. 2. Miseria de la Razón, Razón de la Miseria". En: Gazeta de Antropología. (4). Recuperado de: http:// www.ugr.es/ pwlac/G04_08Pedro_Gomez_Garcia.html\#Resumen

Hawking, S. (1989). Une breve histoire du temps. Du Big Bang aux Trous Noirs. París: Flamarion.

Hegel, G. (1997). Lecciones de Estética. México: Ediciones Coyoacán.

Parménides et. al. (1996). Los Presocráticos. México: Fondo de Cultura Económica.

Prigogine, I. (1996). El fin de las certidumbres. México: Editorial Andrés Bello.

Safranski, R. (2005). El mal o el drama de la libertad. Barcelona: Tusquets.

Schiller, J. (1990). Escritos sobre estética. Madrid: Técnos.

Splenger, O. (2007). La decadencia de Occidente. Tomo I y II. Madrid: EspasaCalpe.

Trías, E. (2000). La edad del espíritu. Barcelona: Ediciones Destino.

Whitehead, A. N. (1999). La función de la razón. Barcelona: Altaya.

Wittgenstein, L. (1981). Tractatus Logicus-Philosophicus. Madrid: Alianza 